Research Article

\title{
Design Optimization of Concrete Aqueduct Structure considering Temperature Effects
}

\author{
Liang-ze-nan Wang and Chao Su iD \\ College of Water Conservancy and Hydropower Engineering, Hohai University, Nanjing 210098, China \\ Correspondence should be addressed to Chao Su; csu@hhu.edu.cn
}

Received 3 October 2020; Revised 26 October 2020; Accepted 29 October 2020; Published 18 November 2020

Academic Editor: Ivan Giorgio

Copyright (c) 2020 Liang-ze-nan Wang and Chao Su. This is an open access article distributed under the Creative Commons Attribution License, which permits unrestricted use, distribution, and reproduction in any medium, provided the original work is properly cited.

\begin{abstract}
An aqueduct is a water conveyance structure that enables channel flow across canals, valleys, depressions, roads, and other structures. The optimal structural selection of the aqueduct is particularly important to ensure engineering quality and optimize project investment. To optimize the design of an aqueduct structure, this study established a mathematical model based on the three-dimensional finite element method that considers the temperature field and structural stress field coupling among its design parameters. The model was used to optimize and design the main wall thickness and tie spacings of the aqueduct structure. The Caohe aqueduct was considered as an example for the proposed design. The influences of temperature-induced stress on the reinforced concrete structure of the aqueduct in winter and summer were investigated based on the actual engineering conditions of the structure, and the corresponding structural optimization was obtained. The results showed that the optimized aqueduct can offset temperature and structural stresses, thus reducing the amount of material required. The maximum generated stress was also lower than that of the original design. Furthermore, this study is expected to provide guidance for similar engineering construction projects.
\end{abstract}

\section{Introduction}

An aqueduct is a water-conveying building that is significantly influenced by water. In particular, the expansion of water during freezing in winter will affect the aqueduct, and floods during summer will increase the water level of the aqueduct. Temperature stresses also influence aqueducts. Thus, an aqueduct structure that uses less material and resists temperature stress is of great significance to water transfer projects.

There are three main types of concrete structures: plain concrete, which has no steel reinforcements, a high compressive strength, and a low tensile strength; reinforced concrete, which can withstand significant tensile stresses due to steel reinforcements; and prestressed concrete, where the concrete is squeezed due to high-strength prestressed steel reinforcement, enabling the resulting precompressive stresses to counteract external loads and increasing the crack resistance of structural members. This study focuses on prestressed concrete aqueducts, which are capable of withstanding considerable tensile and compressive stresses with reduced displacements, thereby preventing cracking [1].

Many reported studies have investigated the optimization of the aqueduct structure. Based on the application of the genetic algorithm to the pi $(\pi)$-type arch aqueduct structure optimization design, Xia et al. [2] verified the feasibility and reliability of the genetic algorithm. Zheng et al. [3] proposed an improved genetic algorithm and applied it to optimize the design of aqueduct structures, revealing improved performance and optimization results. Based on the improved ant colony algorithm, Zhou et al. [4] developed a mixed discrete variable program for optimizing aqueduct structural design, and they demonstrated that this algorithm is reliable and has a strong global convergence ability. Liu [5] attained an economical and reasonable structural form for an aqueduct and its dimensions by optimizing its longitudinal slope, span cross-sectional form, and structural design. Furthermore, this scheme was applied to the Eastern Water Supply Works of Shenzhen city, and the 
economic benefits were validated. Existing reports in the literature do not consider the role of temperature stress during the optimization of aqueduct structures. In particular, for aqueducts spanning long distances and subjected to varying climate conditions, optimizing the structure while accounting for temperature stresses can help reduce the amount of concrete required and the associated costs. In this study, the subproblem method was used for the first optimization calculation of the aqueduct, and the scanning method was used for the second optimization analysis. The results will provide a valuable reference for similar projects [3]. Currently, breakthroughs in the finite element method (FEM) have enabled its widespread application in various fields, including nonlinear analyses of embedded viscoelastic micro composite beams with initial geometrical imperfections [6]. The present study uses the finite element method (FEM) to simulate an aqueduct under a variety of load conditions. Simulations were then performed to optimize the proposed aqueduct design for summer and winter conditions. This study makes a significant contribution to the literature because the optimized structure considering temperature enabled reducing the amount of material required for aqueduct construction by $5-6 \%$.

\section{Establishment of the Model}

2.1. Engineering Profiles. In the simulation, the main riverbed slot side uses a 30-meter-long three-way prestressed reinforced concrete structure with multiple sidewalls (Figure 1). The single slot section is $6.0 \times 5.4 \mathrm{~m}^{2}$. The thickness of the sidewall is $0.6 \mathrm{~m}$, and the pavement plate at the top of the structure is $2 \mathrm{~m}$ wide. The thickness of the middle wall is $0.7 \mathrm{~m}$, and the pavement plate at the top of the structure is $2.7 \mathrm{~m}$ wide. Tie bars are set between the two adjacent walls, and each bar is $2.5 \mathrm{~m}$ long, $0.3 \mathrm{~m}$ wide, and $0.4 \mathrm{~m}$ high. The bars are spaced $2.5 \mathrm{~m}$ apart. The two sidewalls of the water flume part of the aqueduct (without the support section) are equipped with side ribs, and each rib is $0.5 \mathrm{~m}$ wide and $0.7 \mathrm{~m}$ high. The bottom rib is placed at the bottom of the aqueduct. The ribs near the piers are each $0.7 \mathrm{~m}$ wide and $2.0 \mathrm{~m}$ high, and the other ribs are each $0.5 \mathrm{~m}$ wide and $0.9 \mathrm{~m}$ high. Each cross end between two slots has a reserved 0.55 -meter-long postcast strip to allow the workspace for prestressed tensioning. The piers of the structure are of the hollow gravity type, and the foundation is an end-bearing pile; the platform is $26.8 \times 8.5 \times 2.0 \mathrm{~m}^{3}$ (length $\times$ width $\times$ height). Twelve root end-bearing piles are arranged in a double row under the platform.

The prestressed water flume of the aqueduct (without the support section) mainly adopts straight and curved structures; its diameter is $15.2 \mathrm{~mm}$. There are 980 rectilinear steel stranded wires that are of 10 different kinds with 150 channels and a total length of $22,771 \mathrm{~cm}$ (Figure 2). Furthermore, there are 328 curved steel stranded wires (Figure 3), which are of nine different kinds of components with 26 channels and a total length of 25,417.1 cm (Figure 4).
2.2. Finite Element Models. Element selection for the water flume of the aqueduct (without the support section) is the main analytical object of the aqueduct structure. The second object of importance is the steel stranded wire. In this study, the water flume of the aqueduct structure (without support) was regarded as a hydraulic concrete structure for calculations; the Caohe aqueduct is a kind of large-span, highcarrying-capacity aqueduct, in which the simulation of the prestressed steel strands must be considered. This also involves considering the influence of the steel elements in the concrete structure. Two types of elements in the Ansys simulation were introduced as follows [7].

The structural analysis uses Link8 (three-dimensional pole element) elements to simulate the steel strands and Solid45 (three-dimensional element) elements to simulate the concrete components in the finite element software Ansys [8]; this analysis is converted to a thermal analysis after applying the gravity load, water load, wind load, and other loads. The steel strands are changed to the Link33 (three-dimensional pole element) elements for this simulation, and the concrete is changed into the Solid70 element (three-dimensional body element). The temperature is applied in a steady-state thermal convection mode using Ansys to apply the convection temperature from outside the solid. In order to obtain the internal temperature of the solid, a thermal analysis of the aqueduct is performed using the temperature field results, and the node temperature of the thermal analysis is obtained as a body load; when the Ansys thermal analysis is converted into a structural analysis, the body load is read as a load. Finally, the temperature field and stress field of the structure are simultaneously simulated to investigate the stress and strain of the entire structure.

2.3. Establishment of the Aqueduct Model. The structure of the aqueduct is regular and symmetrical, and the design requirement is significant, so it is appropriate to use FEM meshes. The FEM model is shown in Figures 5-8 below.

Figure 6 is an FEM model of the solid aqueduct structure in Figure 5. After applying the mesh, the model contains 50,240 elements and 62,273 nodes.

Figure 7 is the FEM model of the steel strand Cache aqueduct. The steel strand simulation theory shows that curved steel parts in the Caohe aqueduct have complicated conditions. An appropriate constraint equation is used to model the real physical reinforcement. Thus, concrete elements and reinforced node groups were used, and the results are shown in Figure 8.

Figure 8 illustrates that the constraint equation is applied around the steel strands, and the method does not change the node locations; this calculation method is much simpler than the node-coupled method, and the calculation accuracy is higher. Therefore, this method is better for solving the structural force line problem of a complex shape. The modeling problem of the steel-reinforced concrete structure for complex calculation was thus solved. 


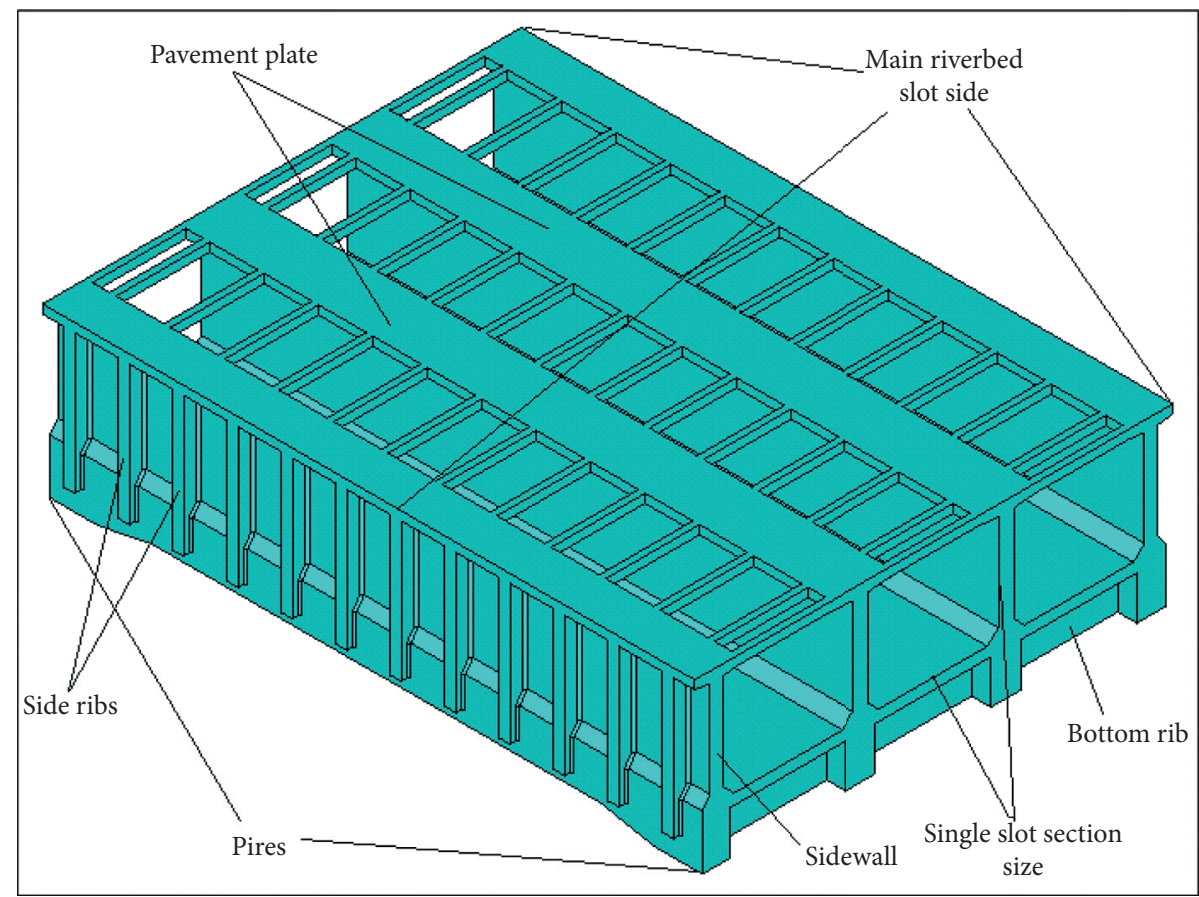

Figure 1: Location of aqueduct structural components.

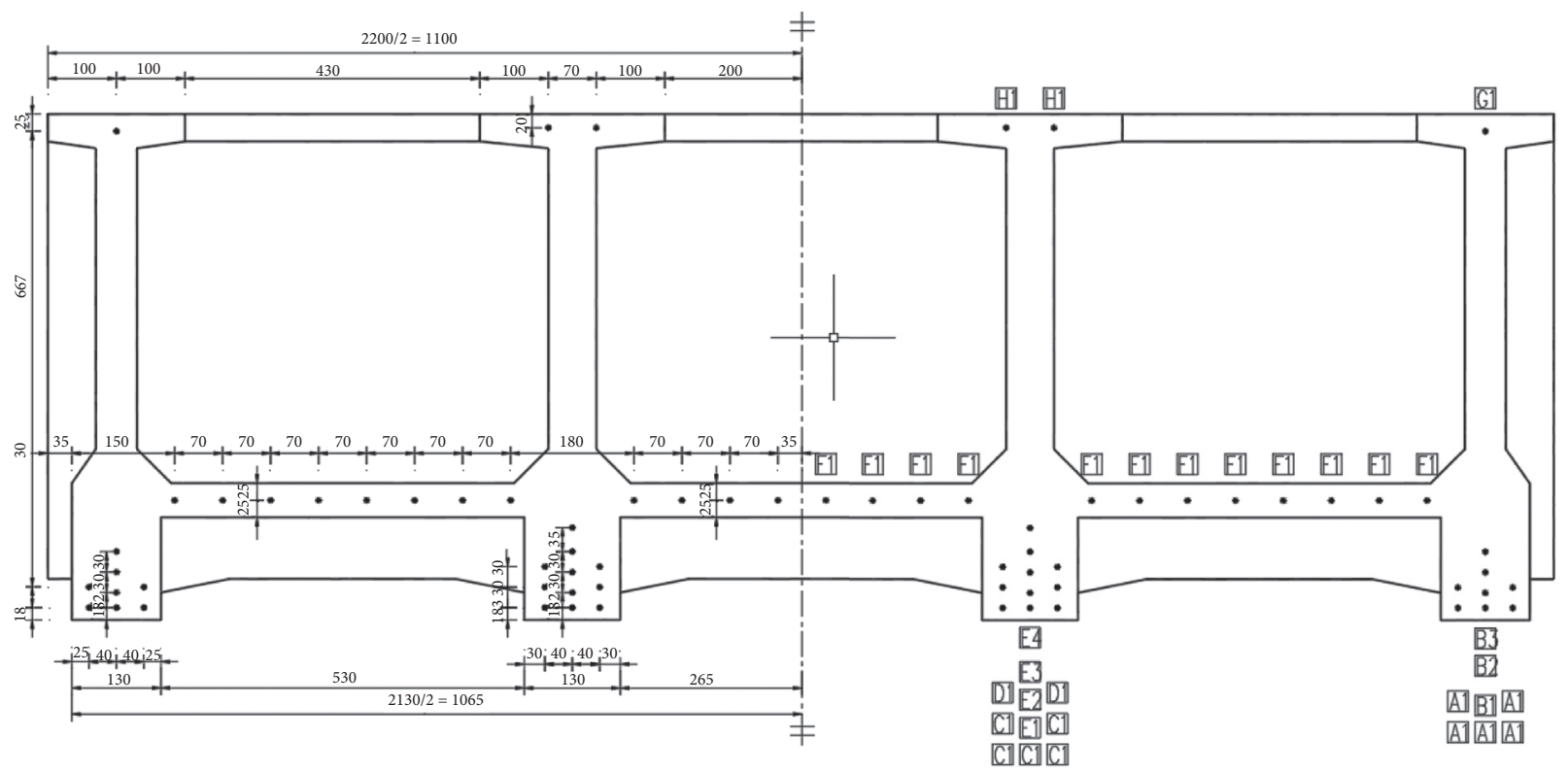

Figure 2: Middle section of the aqueduct (the units are centimeters).

\subsection{Load Effective Combination and Load Distribution on Item}

2.4.1. Load Effective Combination. The water flume part of the stress calculation for the aqueduct structure (without support) considered the following eight combinations. According to the design data, the main aqueduct loads are weight, water, wind, static ice pressure, prestressed force, and temperature action. The combinations of these conditions are summarized in Table 1.
2.4.2. Load Distribution on Item. The listed loads were all standard values according to the design specification for hydraulic concrete structures [9]; when calculating the bearing capacity, these values should be multiplied by the corresponding subcoefficients of the load components.

The self-weight of the structure as a permanent load corresponds to a subcoefficient of 1.05 . The subcoefficients for variable loads include a subcoefficients of 1.1 for water pressure, 1.1 for ice pressure, 1.3 for wind pressure, and 1.1 


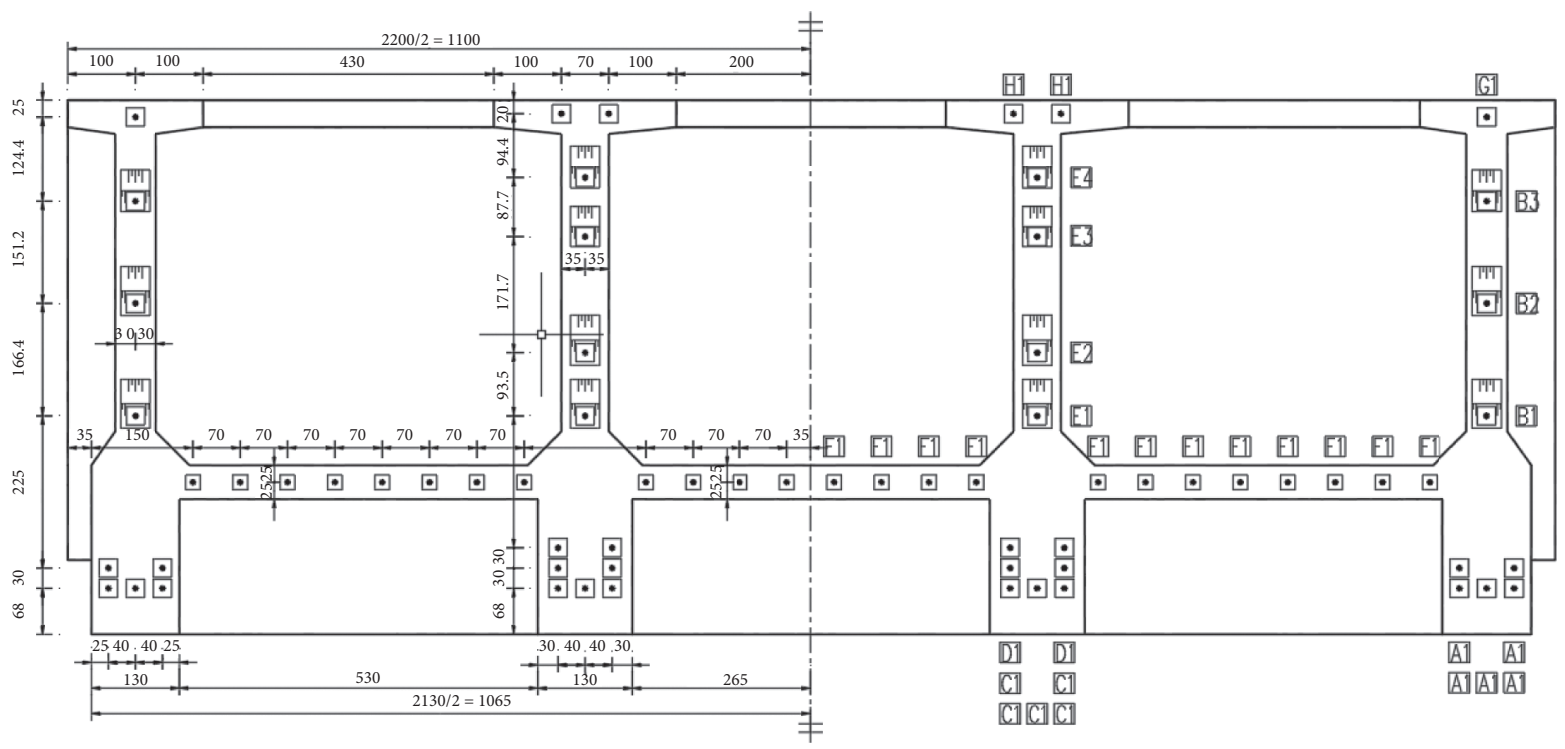

Figure 3: Pier section of aqueduct (the units are centimeters).

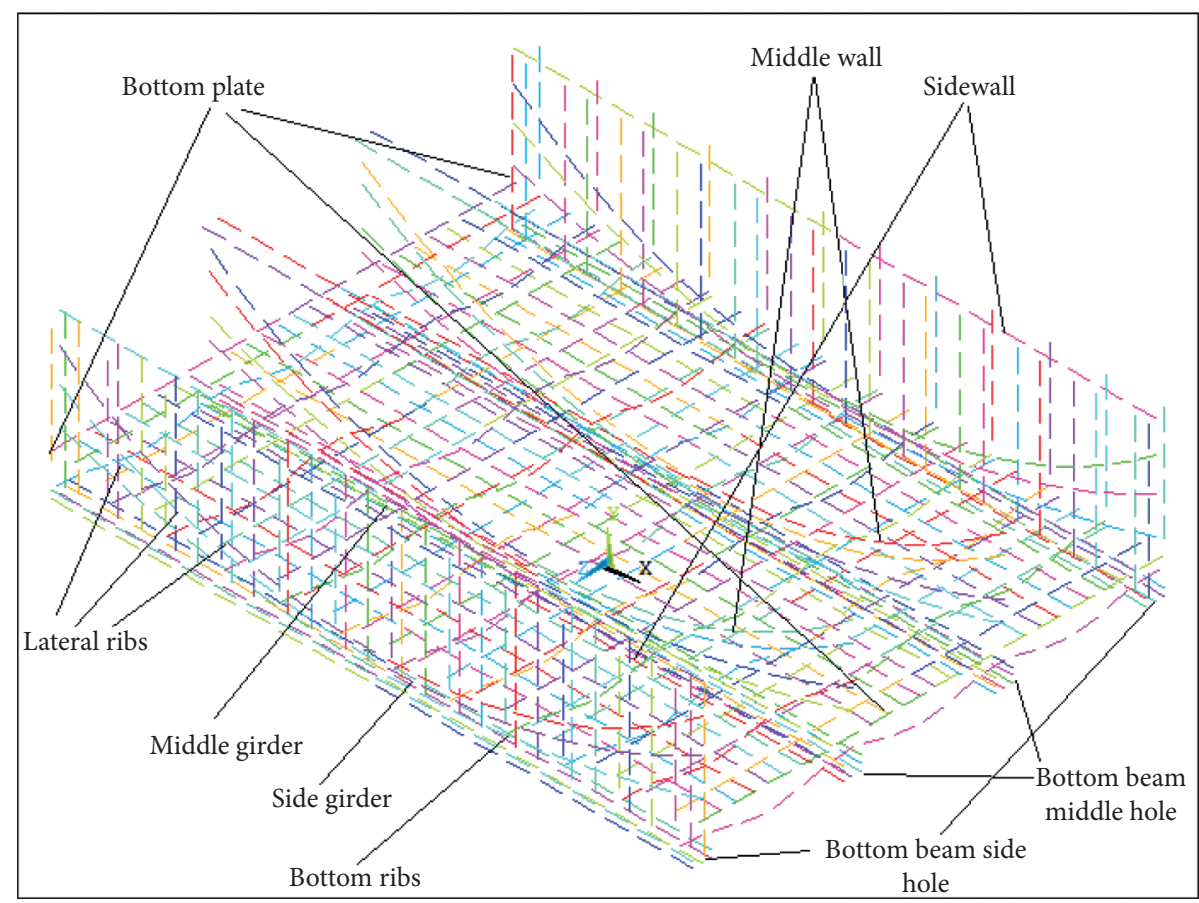

Figure 4: Location of steel stranded line structural components.

for temperature. The designed water depth is $4.150 \mathrm{~m}$, and the increased water depth is $4.792 \mathrm{~m}$. The full tank water depth is $5.400 \mathrm{~m}$.

The wind load is on the windward and leeward faces of the water flume of the aqueduct (without support). The windward standard value is $1.504 \mathrm{kN} / \mathrm{m}^{2}$, and the leeward standard value is $1.504 \mathrm{kN} / \mathrm{m}^{2}$.

When water flows through the aqueduct in summer (according to the working conditions of uniform temperature warming), the temperature calculation was based on the outside surface temperature of the aqueduct $\left(41^{\circ} \mathrm{C}\right)$, the external nighttime temperature was $35^{\circ} \mathrm{C}$, and the tank water temperature was $28^{\circ} \mathrm{C}$. When the water flows through the aqueduct in winter (according to the working conditions of uniform temperature cooling), the temperature calculations were based on an aqueduct external surface temperature of $-10^{\circ} \mathrm{C}$ and a tank water temperature of $4^{\circ} \mathrm{C}$.

The ice thickness was $0.4 \mathrm{~m}$; this impacts the unit length of the building for the static ice pressure standard value of 


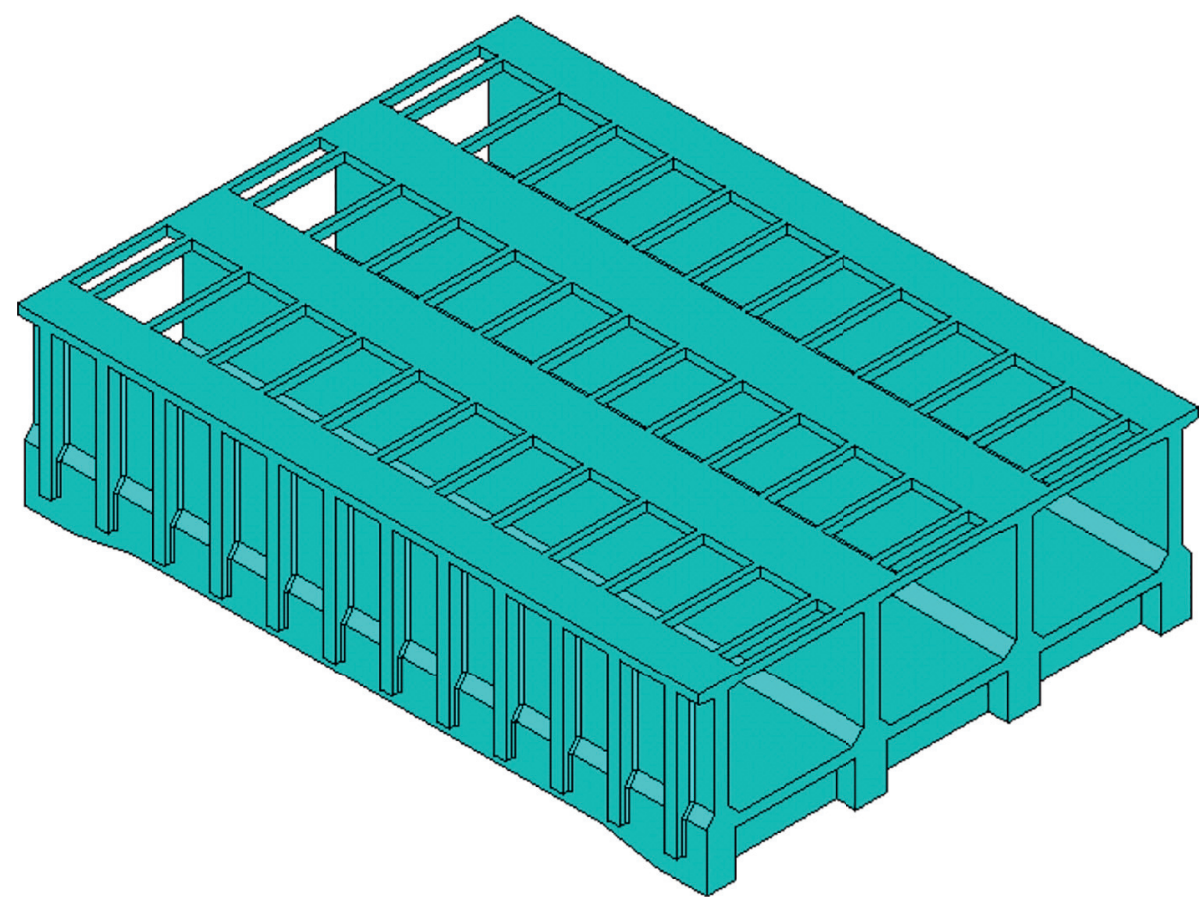

FIgURE 5: Solid model of Caohe aqueduct.

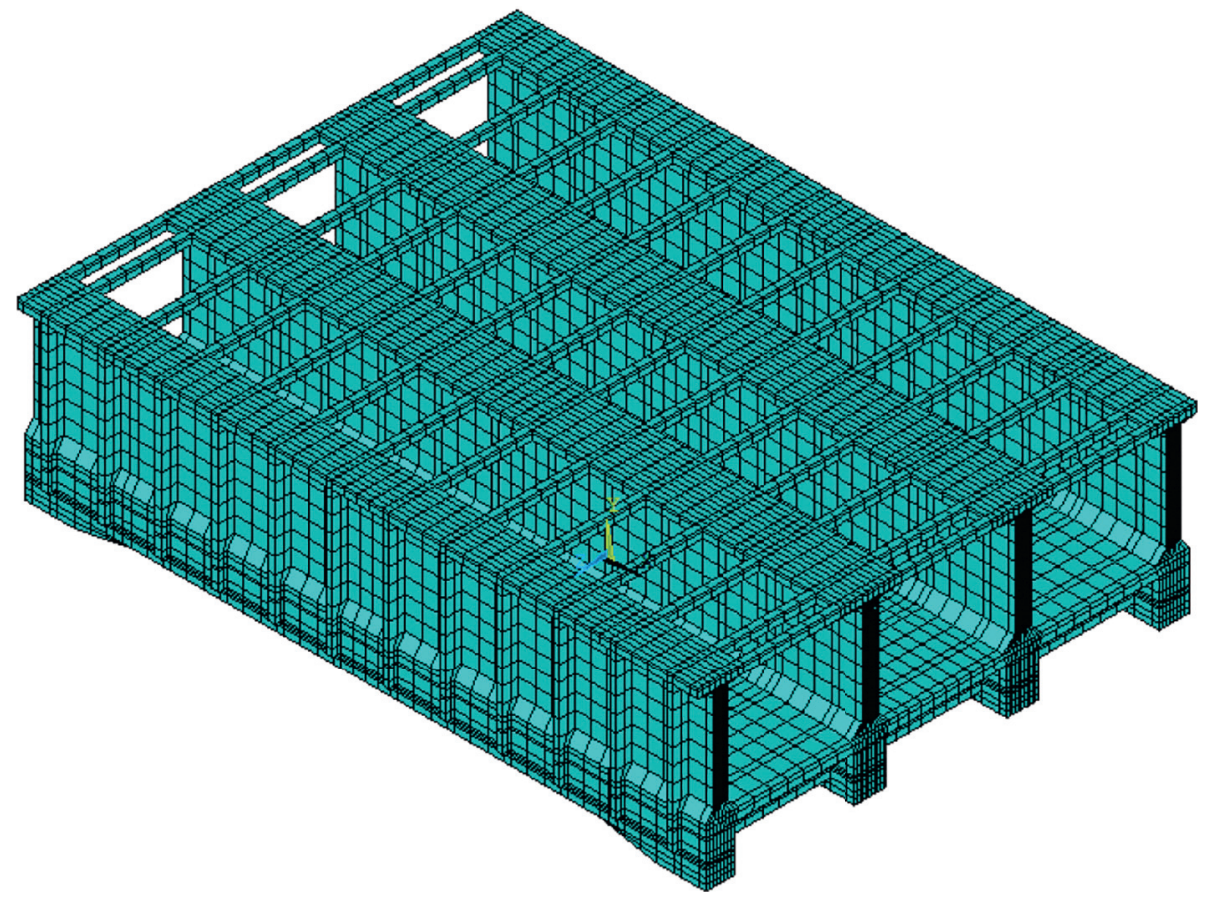

Figure 6: Finite element model of Caohe aqueduct.

$85 \mathrm{kN} / \mathrm{m}$, and the application point is a third of the depth of the ice under the surface [10].

\section{Aqueduct with Three-Dimensional Finite Element Analysis}

\subsection{Calculation Assumptions and Design Parameters}

3.1.1. Structure Assumption. In the $x$-direction, the aqueduct was considered a simply supported beam in the flow direction, and the cross direction is positive. In the $y$-direction, the aqueduct was considered a cantilever beam in the vertical flow direction, and the downward direction is positive. In the $z$-direction, the aqueduct was considered a three-span continuous beam in the transverse view, and the left side of the front view is considered positive.

3.1.2. Temperature Calculation Assumption. The temperature action is steady-state thermal convection modeled using 


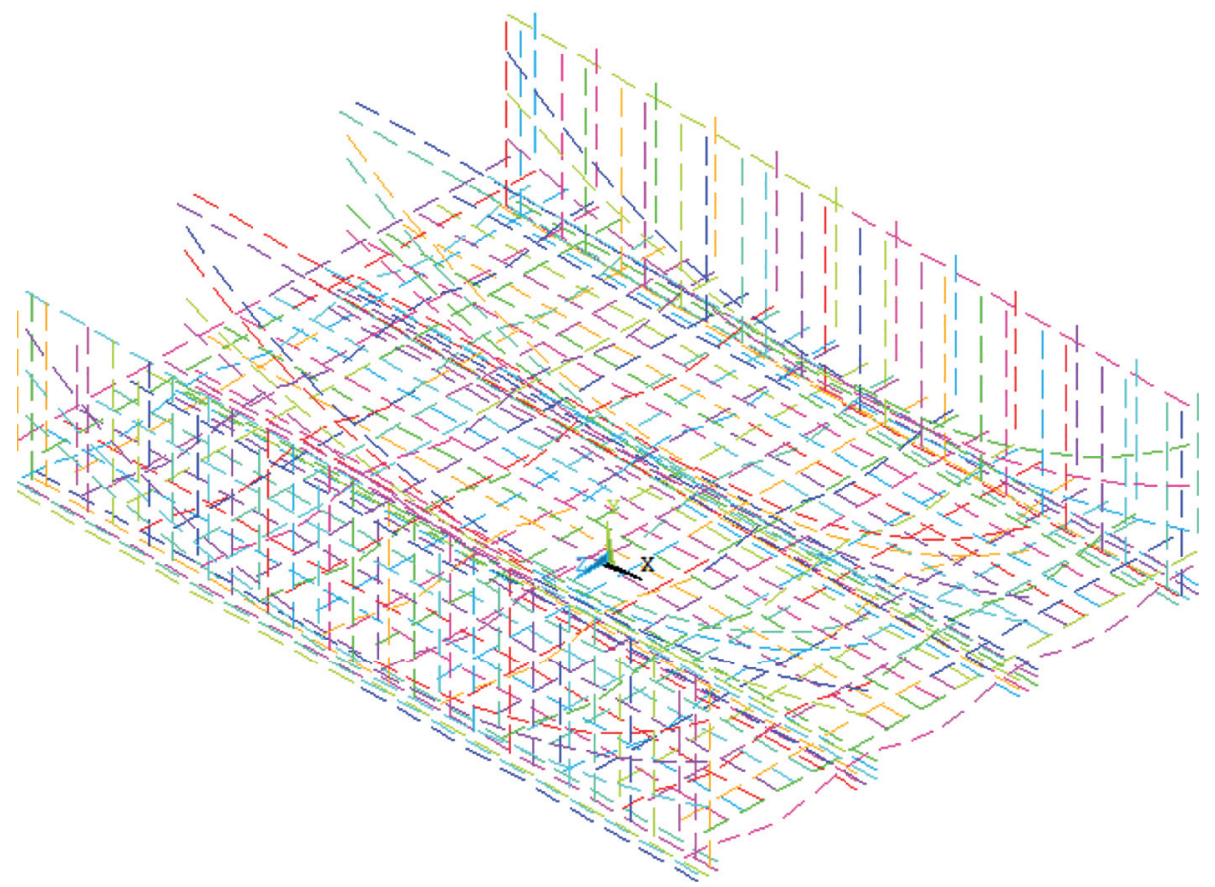

Figure 7: FEM model of steel strand Cache aqueduct.

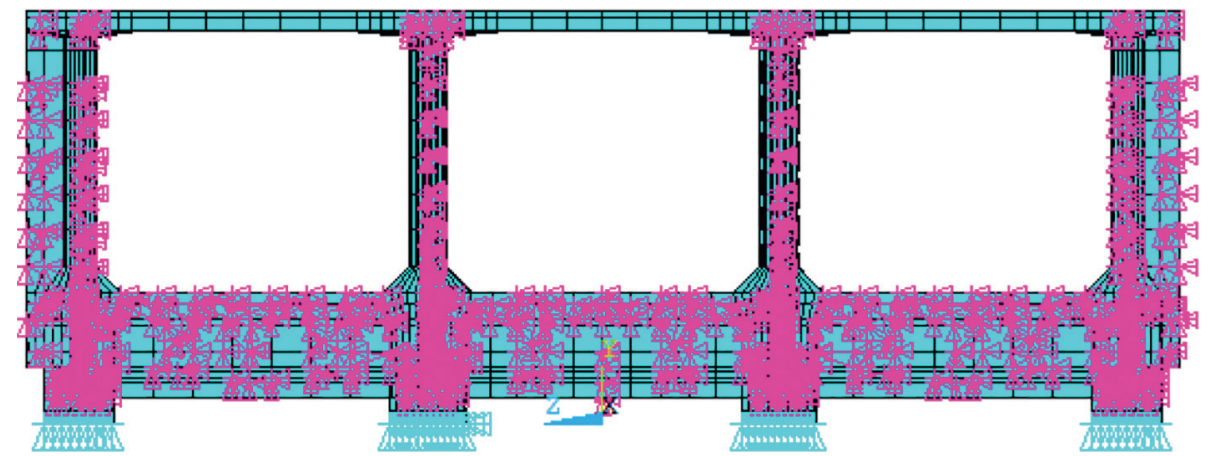

FIGURE 8: Constraint equation of reinforced concrete structure.

TABLE 1: Loads under various working conditions.

\begin{tabular}{lcccccc}
\hline Combination working condition & & & \multicolumn{2}{c}{ Load type } \\
& Weight & Wind & Prestress & Water pressure & Ice pressure & Temperature \\
\hline GK1 & $\sqrt{ }$ & $\sqrt{ }$ & $\sqrt{ }$ & Designed water depth & - & Warming \\
GK2 & $\sqrt{ }$ & $\sqrt{ }$ & $\sqrt{ }$ & Designed water depth & $\sqrt{ }$ & Cooling \\
GK3 & $\sqrt{ }$ & - & $\sqrt{ }$ & Increased water depth & - & Warming \\
GK4 & $\sqrt{ }$ & - & $\sqrt{ }$ & Increased water depth & $\sqrt{ }$ & Cooling \\
GK5 & $\sqrt{ }$ & - & $\sqrt{ }$ & Full tank water depth & - & Warming \\
GK6 & $\sqrt{ }$ & - & $\sqrt{ }$ & Full tank water depth & $\sqrt{ }$ \\
GK7 & $\sqrt{ }$ & $\sqrt{ }$ & - & Built depth without water & - & Cooling \\
GK8 & $\sqrt{ }$ & $\sqrt{ }$ & - & Built depth without water & - & Warming \\
\hline
\end{tabular}

a linear analysis method of sequentially coupled physical fields. A thermal analysis was carried out on the aqueduct, and the results were applied to the conditions of the calculation as the outside load. This kind of calculation method is simple, and the accuracy meets the previously reported requirements [3]. 


\subsubsection{Design Parameter}

(1) Concrete. Strength grade is C50, according to the design specification for hydraulic concrete structures (DL/T50571996), and the structural calculation design parameters are as follows:

Design strength: $f_{c}=23.5 \mathrm{~N} / \mathrm{mm}^{2}, \mathrm{ft}=2.00 \mathrm{~N} / \mathrm{mm}^{2}$, $\mathrm{f}_{\mathrm{ck}}=32.0 \mathrm{~N} / \mathrm{mm}^{2}$, and $\mathrm{f}_{\mathrm{tk}}=2.75 \mathrm{~N} / \mathrm{mm}^{2}$.

Elasticity modulus: Ec $=3.45 \times 104 \mathrm{~N} / \mathrm{mm} 2$, Poisson's ratio: $v=0.167$.

Considering the concrete temperature, coefficient of linear expansion: $8 \mathrm{E}-006 /{ }^{\circ} \mathrm{C}$.

Heat conductivity coefficient: $10 \mathrm{~kJ} /\left(\mathrm{m} \cdot \mathrm{h}^{\circ} \mathrm{C}\right)$.

(2) Stranded Steel Wire of Class 1860. Design strength: $\mathrm{fc}=1860 \mathrm{~N} / \mathrm{mm}^{2}$, elasticity modulus: $\mathrm{E}_{\mathrm{c}}=1.8 \times 105 \mathrm{~N} / \mathrm{mm}^{2}$. Initial strain: $\varepsilon_{\mathrm{s}}=0.007233$, Poisson's ratio: $\nu=0.30$. $\mathrm{m}^{3}$

Stranded steel wire used: $\Phi^{\mathrm{f}} 15.2$, density: $\rho=7850 \mathrm{~kg} /$

(3) Reinforced Concrete. A comprehensive elastic modulus was adopted: $\mathrm{E}_{\mathrm{c}}$ (concrete) $+\mathrm{k}^{*} \mathrm{E}_{\mathrm{c}}$ (elasticity modulus of rebar multiplied by its volume ratio in concrete $)=$ $3.71 \times 104 \mathrm{~N} / \mathrm{mm}^{2}$.

Comprehensive density: $\rho=2400+115=2515 \mathrm{~kg} / \mathrm{m} 3$.

\subsection{FEM Calculations}

3.2.1. Boundary Conditions. According to the conditions of the support constraints (horizontal arrows represent the bearing movement in the vertical flow direction, and vertical arrows represent the bearing movement in the direction of flow), the boundary conditions of the water flume of the aqueduct (without the support) are three constraints in the $x-, y$-, and $z$-directions in the end-circle bearing of the water transfer part of the aqueduct (without the support part), and the remaining three bearings were fixed in the vertical ground and flow directions. The corresponding circle bearing at the other end was fixed in the vertical ground and vertical flow directions, and the remaining three bearings were fixed in the vertical direction (Figure 9).

\subsubsection{Applied Loads}

(1) Self-weight for C50 concrete density: $\gamma=25.0 \mathrm{kN} / \mathrm{m}^{3}$ as the applied inertia load.

(2) Hydrostatic pressure considering water density $\gamma=11 \mathrm{kN} / \mathrm{m}^{3}$ as the surface force on the inner surface of the water flume of the aqueduct (without support).

(3) Wind pressure impacted the side of the water flume of the aqueduct (without support).

(4) Static ice pressure considering $93.5 \mathrm{kN} / \mathrm{m}$ as the impact at a third of the depth of ice under the surface.
(5) The temperature was chosen from among conduction, convection, or radiation heat transfer. This can be used to transform analysis element types into the structural analysis and to apply the winter and summer temperature actions.

The above loads were considered with subcoefficients.

(6) Prestress is applied by the initial strain method.

3.2.3. Calculation Analysis. By using the Ansys software, boundary constraints and loads for the working condition were applied to calculate the stress and strain. The component stress and maximum deformation values of the control section were found on the stress cloud map. The calculation results are shown in Table 2.

Stress Analysis of Key Parts. The calculations show that most parts of the Caohe aqueduct structure were in a state of compression under various conditions and had a partial section in a smaller tensile state. The stress ranges for all parts are listed in Table 3.

Stress Results Summary. Stress in the water flume of the aqueduct (without support) was analyzed under eight working conditions; working conditions 1,3 , and 5 are of the same regularity, and working conditions 2, 4, and 6 are similar as well. The stresses in the water flume of the aqueduct (without support) are satisfactory for all parts; the tensile stress is less than that specified in the design specification for hydraulic concrete structures (DL/T5057-2009) for the allowed range; the compressive stress is not strong, which means that the structural design is reasonable [11]. The control condition is a short-term load condition. With a full tank of water pressure and ice load in the tie bar, the vertical stress in the direction of flow is $1.26 \mathrm{MPa}$ [12].

\section{Aqueduct Structure Optimization Design}

The optimization mainly aims to meet aqueduct safety conditions and conserve engineering materials [13]. The objective function is the minimum total volume of the solid model, and the constraints are that the optimization results are no more than the maximum stress value of the original design scheme, not exceeding the maximum displacement of the original plan [14]. The most representative aqueduct section was selected for optimization, and the subproblem method was chosen for the first optimization, with the scanning method being chosen for the second time $[15,16]$. The aqueduct section size parameters are shown in Figure 10.

The optimization mathematical model was set up to consider the following objective function and constraint conditions: 

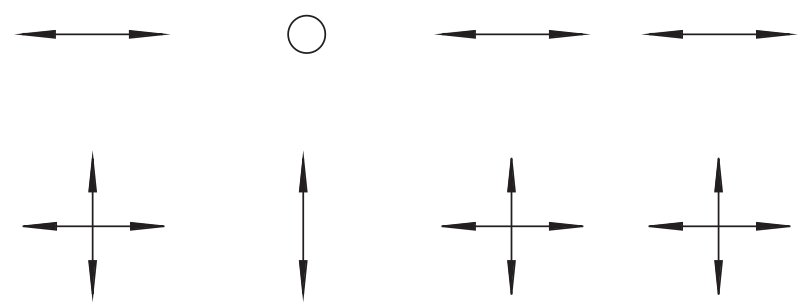

Figure 9: Support constraint.

\begin{tabular}{|cc} 
& 300 \\
& 301 \\
min svolume & 302 \\
$0.35<x_{1}<0.45$ & 303 \\
$0.65<x_{5}<0.75$ & 304 \\
$1.25<x_{6}<1.35$ & 306 \\
$1.35<x_{7}<1.45$ & 307 \\
$5.9<x_{10}<6.1$ & 308 \\
$0.09<x_{11}<1.01$ & 309 \\
$0.65<x_{12}<0.75$ & 310 \\
$0.34<x_{13}<0.36$ & 311 \\
$0.45<x_{14}<0.55$ & 312 \\
$0.95<x_{15}<1.05$ & 313 \\
$5.2<x_{16}<5.4$ & 314 \\
$4.3<x_{17}<4.5$ & 315 \\
$-4.775017264 E-04<D M I N<0$ & 316 \\
$0<$ SMAX $<4534284.69$ & 317 \\
$-19474378.5<$ SMIN $<0$ & 318 \\
& 319 \\
& 320 \\
& 321 \\
& 322 \\
\hline
\end{tabular}

where svolume is the total volume. DMIN is the smallest value of displacement, SMAX is the maximum stress, and SMIN is the minimum stress. The variables were not optimized, which used the original design values [17]. The water load was imposed in accordance with the full tank water depth [18]. The optimized design variable values are shown in Table 4.

This optimization mainly satisfies three constraints: first, the maximum absolute value of displacement does not exceed the original design value of $4.78 e-4 \mathrm{~m}$; second, the maximum tensile stress value does not exceed the original design value of $4.53 \mathrm{MPa}$; and third, the maximum compressive stress value does not exceed the original design value of 19.47 MPa. In case the abovementioned conditions are satisfied, a design solution that reduces the volume can be obtained. The volume of the aqueduct is calculated by stretching its cross section; therefore, in this study, the crosssectional area of the optimized aqueduct is used instead of the optimized aqueduct volume. In other words, to calculate the optimal solution, it is necessary to ensure that the maximum values of displacement and strain are less than the maximum values in the original design. Subsequently, the minimum cross-sectional area of the aqueduct needs to be determined. Reducing the cross-sectional area of the aqueduct is equivalent to reducing the volume of the aqueduct.

The summer and winter project body temperature distributions are shown in Figures 11 and 12, respectively. The top part of the aqueduct temperature in contact with the water remained the same as the water temperature, and the temperature change was mainly in the sidewalls.

The volume of the original design project is 73.55 , and the summer optimization solution is 69.82 ; i.e., it reduced by 3.73 or about $5.07 \%$. Thus, this design can save about $5.07 \%$ of the C50 concrete dosage. The winter optimization solution is 68.95 , reduced by 4.6 or about $6.25 \%$, so this design can save about $6.25 \%$ of the C50 concrete dosage.

For different regional climate conditions, the summer project is more suitable for regions with a long summer, and the winter project is more suitable for those with a long winter $[19,20]$.

\section{Summary}

The summer optimization solution is used for areas experiencing long periods of hot weather, whereas the winter optimization solution is used for areas experiencing long periods of cold weather. For the summer optimization solution, the left and right sides of the aqueduct are considered to have different temperatures, considering that only one side faces the sun at most times. The high specific heat capacity of water is not easily affected by temperature; hence, water temperature is mainly regarded as a constant temperature in the calculation. The results show that the temperature of the inner side of the aqueduct in contact with water is basically the same as the water temperature, which is approximately $28^{\circ} \mathrm{C}$; on moving from the inside of the aqueduct to its outside, an increasing temperature gradient is observed. In the winter optimization project, the temperature of the left and right sides is considered to be $-10^{\circ} \mathrm{C}$ because the influence of the sun is limited during winter. The water temperature inside the aqueduct is $4^{\circ} \mathrm{C}$, and there is no ice. The calculations show that the point of contact between water and the aqueduct is maintained at the same temperature of $4^{\circ} \mathrm{C}$, and a decreasing temperature gradient is observed from the inside of the aqueduct to its outside.

Winter optimization project used $1.18 \%$ less material than the summer project. Considering the heat bilges cold shrink phenomenon of the material, the aqueduct volume in summer is larger than that in winter, so the temperature stress is larger than that in the winter. Thus, the summer structure needs to bear more temperature stress, and it requires more material. This optimization project conforms to the actual engineering situation. For areas with different temperature conditions, optimization considers the 
TABLE 2: Stress value of each working condition of the control section (unit: MPa).

\begin{tabular}{|c|c|c|c|c|c|c|c|c|c|c|}
\hline \multirow{2}{*}{\multicolumn{2}{|c|}{$\begin{array}{l}\text { Part } \\
\text { Working } \\
\text { condition }\end{array}$}} & \multicolumn{2}{|c|}{$\begin{array}{l}\text { End of longitudinal beam } \\
\text { across }\end{array}$} & \multicolumn{2}{|c|}{ Baseboard } & \multirow{2}{*}{$\begin{array}{l}\text { Bottom floor } \\
\text { middle span }\end{array}$} & \multirow{2}{*}{ Edge rib } & \multirow{2}{*}{ Tie bar } & \multicolumn{2}{|c|}{ Aqueduct top } \\
\hline & & Center hole & Side hole & Upper surface & Lower surface & & & & Middle wall & Sidewall \\
\hline \multirow{4}{*}{1} & $x$ & 1.75 & 1.75 & -0.081 & 0.836 & -0.081 & -0.081 & -0.081 & -3.75 & -3.75 \\
\hline & $y$ & -1.15 & -1.15 & -1.15 & -1.15 & -1.15 & -1.15 & -1.15 & -1.15 & -1.15 \\
\hline & $z$ & -0.283 & -0.283 & -1.25 & 0.36 & 1 & 0.038 & -0.927 & -0.283 & -0.283 \\
\hline & $x$ & 1.75 & 1.75 & -0.081 & 0.836 & -0.081 & -0.081 & -0.081 & -3.75 & -3.75 \\
\hline \multirow[t]{3}{*}{2} & $y$ & -1.15 & -1.15 & -1.15 & -1.15 & -1.15 & -1.15 & -1.15 & -1.15 & -1.15 \\
\hline & $z$ & -0.283 & -0.283 & -1.25 & 0.36 & 1 & 0.038 & -0.927 & -0.283 & -0.283 \\
\hline & $x$ & 1.87 & 1.87 & -0.052 & 0.91 & -0.052 & -0.052 & -0.052 & -3.90 & -3.90 \\
\hline \multirow[t]{3}{*}{3} & $y$ & -1.17 & -1.17 & -1.17 & -1.17 & -1.17 & -1.17 & -1.17 & -1.17 & -1.17 \\
\hline & $z$ & -0.271 & -0.271 & -0.097 & 0.42 & 1.12 & -0.271 & -0.271 & -0.007 & -0.007 \\
\hline & $x$ & 1.87 & 1.87 & -0.052 & 0.91 & -0.052 & -0.052 & -0.052 & -3.90 & -3.90 \\
\hline \multirow[t]{3}{*}{4} & $y$ & -1.17 & -1.17 & -1.17 & -1.17 & -1.17 & -1.17 & -1.17 & -1.17 & -1.17 \\
\hline & $z$ & -0.271 & -0.271 & -0.097 & 0.42 & 1.12 & -0.271 & -0.271 & -0.007 & -0.007 \\
\hline & $x$ & 1.98 & 1.98 & -0.06 & 0.958 & -0.06 & -0.06 & -0.06 & -6.17 & -6.17 \\
\hline \multirow[t]{3}{*}{5} & $y$ & -1.26 & -1.26 & -1.26 & -1.26 & -1.26 & -1.26 & -1.26 & -1.26 & -1.26 \\
\hline & $z$ & -0.255 & -0.255 & -1.01 & 0.495 & 1.25 & -0.255 & -0.255 & -0.255 & -0.255 \\
\hline & $x$ & 1.98 & 1.98 & -0.06 & 0.958 & -0.06 & -0.06 & -0.06 & -6.17 & -6.17 \\
\hline \multirow[t]{3}{*}{6} & $y$ & -1.26 & -1.26 & -1.26 & -1.26 & -1.26 & -1.26 & -1.26 & -1.26 & -1.26 \\
\hline & $z$ & -0.255 & -0.255 & -1.01 & 0.495 & 1.25 & -0.255 & -0.255 & -0.255 & -0.255 \\
\hline & $x$ & 1.02 & 1.02 & -0.032 & 0.495 & -0.032 & -0.032 & -0.032 & -2.14 & -2.14 \\
\hline \multirow[t]{3}{*}{7} & $y$ & -0.606 & -0.606 & -0.606 & -0.606 & -0.606 & -0.606 & -0.606 & -0.606 & -0.606 \\
\hline & $z$ & -0.164 & -0.164 & 0.205 & -0.349 & 0.205 & -0.164 & -0.349 & -0.020 & -0.020 \\
\hline & $x$ & 1.02 & 1.02 & -0.032 & 0.495 & -0.032 & -0.032 & -0.032 & -2.14 & -2.14 \\
\hline \multirow[t]{2}{*}{8} & $y$ & -0.606 & -0.606 & -0.606 & -0.606 & -0.606 & -0.606 & -0.606 & -0.606 & -0.606 \\
\hline & $z$ & -0.164 & -0.164 & 0.205 & -0.349 & 0.205 & -0.164 & -0.349 & -0.020 & -0.020 \\
\hline
\end{tabular}

TABLE 3: All parts of the aqueduct and their corresponding stress ranges.

\begin{tabular}{lcc}
\hline Parts & Stress range & Stress direction \\
\hline Beam bottom of the center hole & $-1.26-1.98 \mathrm{MPa}$ & GK6 vertically in the direction of flow, GK6 in the direction of flow \\
Beam bottom of the edge hole & $-1.26-1.98 \mathrm{MPa}$ & GK5 vertically in the direction of flow, GK6 in the direction of flow \\
Above the floor & $-1.26-0.205 \mathrm{MPa}$ & GK5 in the direction of flow, GK8 gravity flow direction \\
Below the floor & $-1.26-0.958 \mathrm{MPa}$ & GK5 vertically in the direction of flow, GK5 in the direction of flow \\
In the bottom ribs across & $-1.26-1.25 \mathrm{MPa}$ & GK5 vertically in the direction of flow, GK6 gravity flow direction \\
Edge rib & $-1.26-0.038 \mathrm{MPa}$ & GK5 vertically in the direction of flow, GK2 gravity flow direction \\
Tie bar & $-1.26--0.032 \mathrm{MPa}$ & GK5 vertically in the direction of flow, GK8 in the direction of flow \\
Middle wall & $-6.17--0.007 \mathrm{MPa}$ & GK5 in the direction of flow, GK4 gravity flow direction \\
Sidewall & $-6.17--0.007 \mathrm{MPa}$ & GK5 in the direction of flow, GK4 gravity flow direction \\
\hline
\end{tabular}

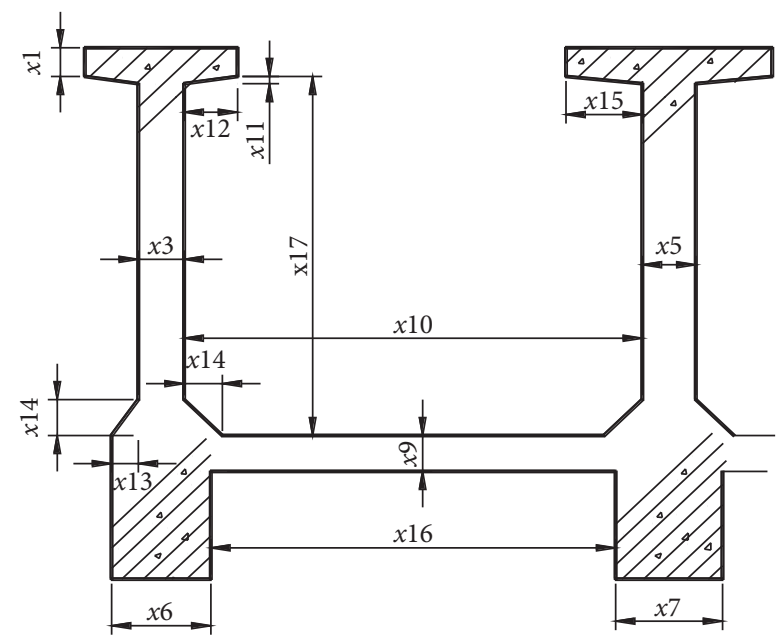

Figure 10: Aqueduct section size parameters (units are meters). 
TABLE 4: Optimized design variable values (unit: meter).

\begin{tabular}{|c|c|c|c|c|c|c|c|c|c|c|c|c|c|}
\hline Project & $x 1$ & $x 3$ & $x 5$ & $x 6$ & $x 7$ & $x 10$ & $x 11$ & $x 12$ & $x 13$ & $x 14$ & $x 15$ & $x 16$ & $x 17$ \\
\hline Original project & 0.4 & 0.6 & 0.7 & 1.3 & 1.4 & 6 & 0.1 & 0.7 & 0.35 & 0.5 & 1 & 5.3 & 4.4 \\
\hline Summer project & 0.35 & 0.55 & 0.65 & 1.27 & 1.35 & 6.04 & 0.09 & 0.65 & 0.35 & 0.54 & 0.99 & 5.33 & 4.5 \\
\hline Winter project & 0.35 & 0.55 & 0.65 & 1.25 & 1.35 & 6.09 & 0.09 & 0.65 & 0.34 & 0.45 & 0.97 & 5.2 & 4.5 \\
\hline
\end{tabular}
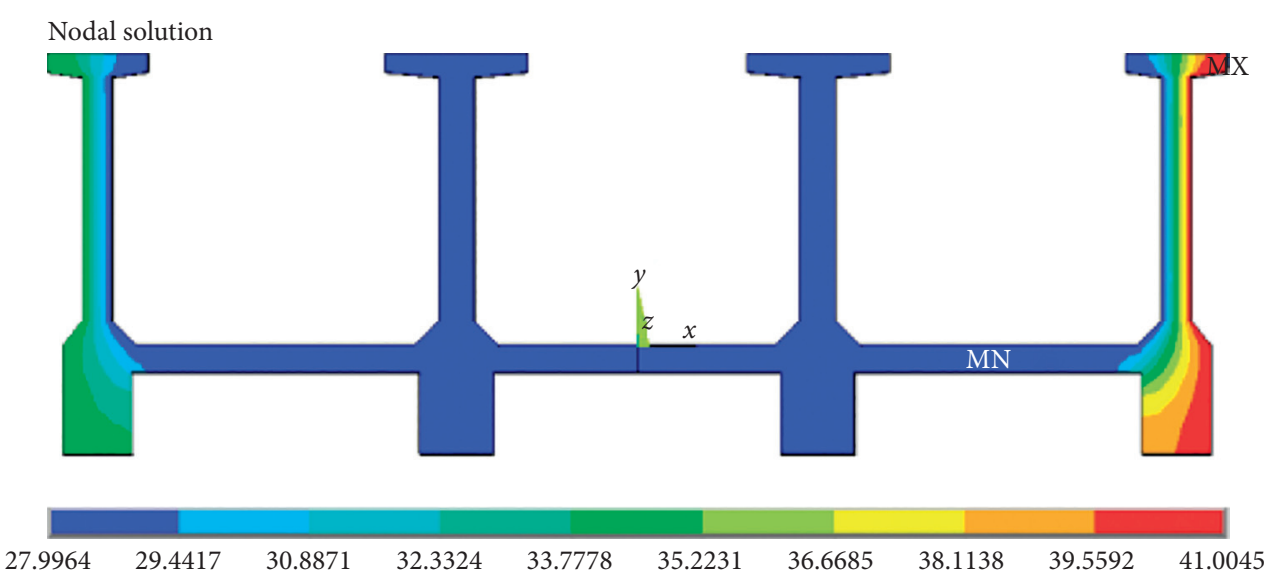

Figure 11: Summer project body temperature.

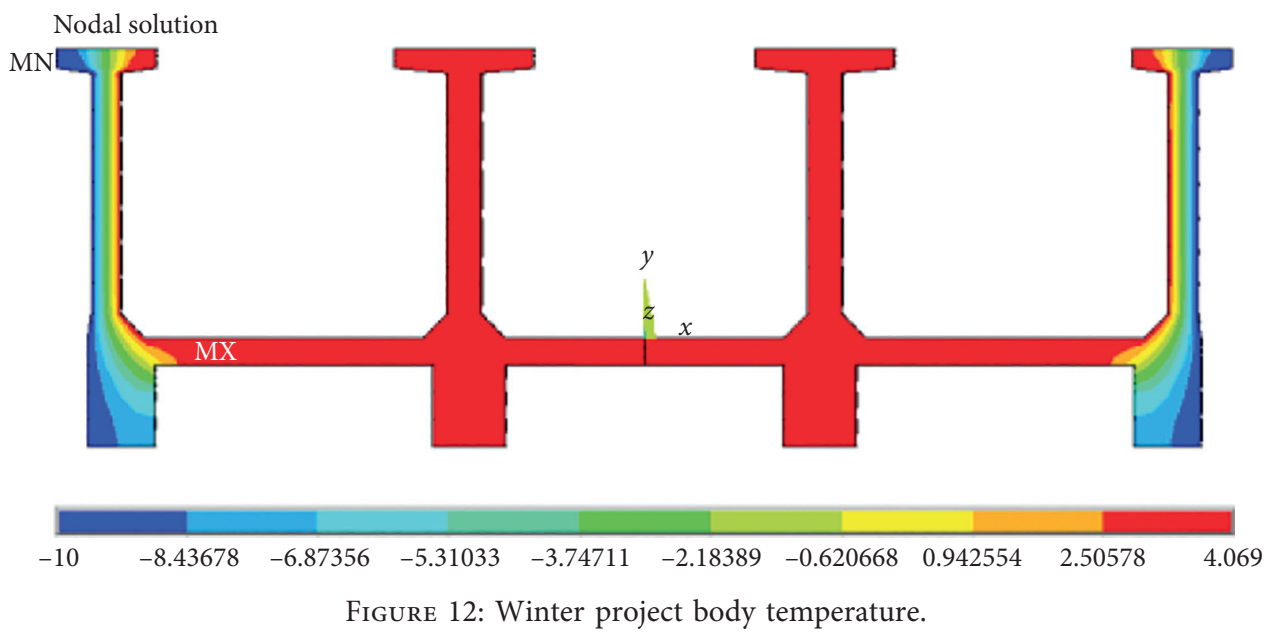

temperature that can conserve more materials. The optimization in the high-temperature region uses a high-temperature action. In a region of low temperature, the optimization runs under a low-temperature action. This work mainly studied the optimization of the maximum water load under different temperature conditions because the water load widely influences the structure of the maximum stress and displacement in the optimization is no more than the original design project, and the concrete dosage was optimized to be $5.07 \%$ and $6.25 \%$ less that the original material usage, respectively. Under the summer and winter temperature conditions, this study can provide theoretical references for similar projects.

\section{Data Availability}

The data used to support the findings of this study are included within the article.

\section{Conflicts of Interest}

The authors declare that there are no conflicts of interest regarding the publication of this paper.

\section{Acknowledgments}

This study was funded by the National Natural Science Foundation of China (Grant no. 51579089).

\section{References}

[1] F. Bourada, A. Tounsi, S. R. Mahmoud et al., "Stability and dynamic analyses of SW-CNT reinforced concrete beam resting on elastic-foundation," Computers and Concrete, vol. 25, no. 6, pp. 485-495, 2020.

[2] F. Z. Xia, D. H. Huang, and C. Y. Fang, "Structural optimization design of $\pi$-shaped arched aqueduct based on 
genetic algorithm," Journal of Wuhan University of Hydraulic \& Electric Engineering, vol. 38, pp. 23-26, 2005.

[3] C. Y. Zheng, H. Peng, Q. L. Yan, and S. Liu, "Application of improved genetic algorithm in structural optimization design of aqueduct," Journal of Yangtze River Scientific Research Institute vol. 29, 2012.

[4] J. Zhou, L. Jiang, X. Liu, and X. Bai, "Structural optimization design of aqueduct by improved ant colony algorithm," Yangtze River vol. 41, 2010.

[5] X. Liu, "The optimization design and achieve of aqueduct structure," Journal of Wuhan University of Hydraulic \& Electric Engineering vol. 34, 2001.

[6] S. Alimirzaei, M. Mohammadimehr, and T. Abdelouahed, "Nonlinear analysis of viscoelastic micro-composite beam with geometrical imperfection using FEM: MSGT electromagneto-elastic bending, buckling and vibration solutions," Structural Engineering \& Mechanics, vol. 71, no. 5, pp. 485502, 2019.

[7] J. W. Zhang and D. Wei, "Applications of genetic algorithm in aqueduct's optimization design," Applied Mechanics and Materials, vol. 438-439, pp. 1137-1140, 2013.

[8] S. Wang and F. Ma, "Reinforced concrete frame structure based on ANSYS optimization analysis and material properties," Advanced Materials Research, vol. 788, pp. 571-574, 2013.

[9] Chinese Standard Net, Design Specification for Hydraulic Concrete Structures, National Energy Administration of the People's Republic of China, Beijing, China, 1996.

[10] X.-C. Wang, W.-G. Lan, and S.-B. Zhao, "Research on structural arrangement optimization design of prestressed concrete multi-longitudinal-beams aqueduct," Journal of North China Institute of Water Conservancy \& Hydroelectric Power vol. 29, 2008.

[11] Z. Z. Zhang and S. U. Chao, "Continuum topology optimization method for arch axis design of arciform aqueducts," Journal of Hohai University, vol. 35, no. 4, pp. 444-447, 2007.

[12] X. L. Bai, W. Yu, D. F. Wang, and Y. Y. Fan, "Improved genetic algorithms based optimal design of the Shuangji river aqueduct," Advanced Materials Research, vol. 201-203, pp. 1288-1291, 2011.

[13] K. P. Georgakakos and R. H. Galarraga Sánchez, "On leastcost design of aqueduct systems," Journal of Water Resources Planning and Management, vol. 115, no. 4, pp. 486-502, 1989.

[14] W. Yao, P. Huang, and H. Peng, "Notice of retraction application of improved genetic algorithm in prestressed aqueduct structural optimal design," in Proceedings of the International Conference on Computer Application and System Modeling, Taiyuan, China, November 2010.

[15] J. Sathaye and W. A. Hall, "Optimization of design capacity of an aqueduct," Journal of Irrigation \& Drainage Engineering, vol. 102, pp. 295-305, 1976.

[16] Y Li, X. Bai, and Z. Wu, "The determination of optimal design plan of the sha-he aqueduct," in Proceedings of the, IEEE International Conference on Information Management and Engineering, pp. 319-323, IEEE, Chengdu, China, June 2010.

[17] Y. Zhao, J. W. Zhang, and Y. N. Zhang, "Application of GA toolbox based on matlab 7.0 to optimal design of aqueduct," Water Resources \& Hydropower Engineering vol. 36, 2005.

[18] J. F. Guan, X. K. Li, and S. B. Zhao, "Structural optimization of reinforced concrete aqueduct with multi-longitudinal beams part II: application," Advanced Materials Research, vol. 243-249, pp. 323-326, 2011.
[19] C. Resina, "A general method for solving constrained optimization problems," European Journal of Operational Research, vol. 21, no. 1, pp. 93-100, 1985.

[20] X.-M. Lu, Y. Zhao, Q.-W. Ren, and P. Li, "Optimization design of prestressing tendon without bond in U-shape aqueduct bridge," Hydro-Science and Engineering, vol. 29, no. 2, pp. 55-60, 2009. 